\title{
In Vitro Introduction of Hardy Alcohol Resistant Bacillus spp. through Aseptically Grown Watermelon Seedlings
}

\author{
Pious Thomas*, Chennareddy Aswath \\ Division of Biotechnology, Indian Institute of Horticultural Research, Bangalore, India \\ Email: ${ }^{*}$ ioust@gmail.com, ${ }^{*}$ pioust@iihr.ernet.in
}

Received 3 May 2014; revised 5 June 2014; accepted 3 July 2014

Copyright (C) 2014 by authors and Scientific Research Publishing Inc.

This work is licensed under the Creative Commons Attribution International License (CC BY). http://creativecommons.org/licenses/by/4.0/

c) (i) Open Access

\begin{abstract}
The present study was taken up with a view to ascertain the possibility of introduction of alcohol resistant bacteria in vitro through the aseptically raised watermelon (Citrullus lanatus) seedlings in the backdrop of isolating such organisms from micropropagated watermelon stocks. Watermelon cv. Arka Manik seedlings grown in vitro from surface-sterilized seeds with the intact seed coat on MS medium appeared visibly clean largely, but upon subjecting them to tissue-indexing, the segments from the collar or root tissue showed bacterial colony growth on Nutrient Agar (NA) from $72 \%$ of such healthy seedlings and the cotyledon and hypocotyl tissue of $44 \%$ seedlings. The pooled colony growth from NA upon challenge with $90 \%$ alcohol yielded 10 distinct colony types, identified as B. pumilus (4×), B. subtilis $(4 \times)$, B. cereus $(1 \times)$ or $B$. safensis $(1 \times)$ based on partial $16 S$ rRNA sequence analysis. The shoot-tip tissue from the healthy index-negative seedlings cultured on watermelon proliferation medium partly turned index-positive within 2 - 4 sub-culture cycles while being apparently clean. On the other hand, those from the previously index-positive cultures tended to show obvious bacterial growth during subsequent in vitro culturing. The observations suggested the possibility of introduction of spore-forming Bacillus spp. through surface-sterilized seeds, their gradual emergence in vitro in visibly clean seedlings, possible transmittal of spores to the alcohol through tissue-culturing tools and the survival therein with the chances of unsuspected lateral spread. Seed coat removal followed by surface sterilization with sodium hypochlorite facilitated the raising of clean seedlings with no detectable bacterial association.
\end{abstract}

\section{Keywords}

Alcohol Resistant Bacteria, Hardy Bacillus spp., Bacterial Endospores, Microbial Contamination, Micropropagation, Plant Tissue Culture

\footnotetext{
*Corresponding author.
} 


\section{Introduction}

Microbial contamination is a serious limiting factor with plant tissue culture research and commercial production units [1]-[3]. Alcohol dip and flaming is employed as a common sterilization technique for disinfecting instruments like forceps and scalpels in plant tissue culture research and industry [4]-[6]. Recent studies have indicated that alcohol once got contaminated with the hardy spores of bacteria like Bacillus, Brevibacillus, Lysinibacillus or Paenibacillus spp., the spores could survive therein for long periods, and the adulterated alcohol could serve as a source of inoculum leading to the unsuspected lateral spread of contaminants [6] [7]. At this laboratory, two alcohol surviving bacteria were initially isolated from the micropropagated cultures of grapes as covertly associated endophytic colonizers, namely B. pumilus [8] and Brevibacillus sp., the latter an uncommon Gram-negative spore-former [9]. Subsequently, five different Bacillus spp., namely, Bacillus megaterium, B. fusiformis, B. pumilus, B. subtilis and B. flexus were isolated from the spent alcohol used towards the disinfection of culture handling tools of micropropagated triploid watermelon [10]. The spores of the above organisms showed survival in ethanol for varying periods to the tune of over one year depending on the concentration of ethanol, the organism involved, stage of growth of source culture, spore content and the growing conditions [7]-[10].

The association of different bacteria in covert or inconspicuous form was found to be the cause of the unprecedented degeneration or decline in the performance of micropropagated cultures [11]. The cultures of elite triploid seedless watermelon were cleansed through a combination of surface sterilization and antibiotic challenge coupled with recurrent medium- and tissue-indexing [12]. The watermelon culture in question had gone through over six years of continuous in vitro culturing before the initial isolation of alcohol-resistant Bacillus spp. [10], and it was unclear whether they were introduced at the time of culture establishment through the plant material or as lateral contaminants later on. The present study was taken up with a view to ascertain the possibility of introduction of alcohol resistant bacteria in vitro through the aseptically raised watermelon seedlings to clarify this obscurity so that appropriate contamination control strategies could be adopted.

\section{Materials and Methods}

\subsection{Seed and Plant Material}

Seeds of diploid watermelon (Citrullus lanatus [Thunb.] Matsum. \& Nakai) cv. Arka Manik were surface sterilized by soaking in $90 \%$ ethanol for 1 min followed by 5 min treatment with $0.1 \% \mathrm{HgCl}_{2}$ containing $0.01 \%$ Tween-20. Use of $\mathrm{HgCl}_{2}$ was warranted as the alternate disinfectants sodium hypochlorite and chlorine water induced high yellowish exudates from the seed coat which could not be contained even with their recurrent sub-culturing to fresh medium. The $\mathrm{HgCl}_{2}$ treated seeds were rinsed in sterile distilled water six times and were imprinted on Nutrient Agar (NA) with the parallel plating of the last two wash solutions on NA to ensure the effectiveness of surface sterilization treatments. The seeds were cultured singly in glass tubes $(150 \times 25 \mathrm{~mm})$ containing $15 \mathrm{ml}$ autoclaved Murashige and Skoog (MS) medium [13] with $30 \mathrm{~g} \cdot \mathrm{l}^{-1}$ sucrose and $8 \mathrm{~g} \cdot \mathrm{l}^{-1}$ agar. The cultures showing any obvious or inconspicuous contamination were discarded as originating from inefficient surface disinfection. The visibly clean seedling cultures were subjected to the indexing of medium [11] [12] by transferring small bits of culture medium to NA at two week stage. The shoot-tips from the seedlings that had tested negative during medium-indexing were excised at 3-wk stage and were transferred to Watermelon Proliferation Medium (WPM) [11] [12] in culture bottles. At this stage, the tissue segments from the shoot, collar and roots were indexed on NA to check for any bacterial association [12].

\subsection{Isolation and Purification of Bacteria}

The colony growths that emerged on NA following the indexing of medium/tissue from the visibly clean seedlings after 3 - 4 days of incubation at $30^{\circ} \mathrm{C}$ were used in further investigations. These cultures were confirmed for spore production under 1000× phase-contrast using a Leica DM 2000 optical microscope (Leica Microsystems CMS GmbH, Wetzlar, Germany). The sporulating cultures from different seedlings were pooled and challenged with filter sterilized $90 \%$ alcohol for $24 \mathrm{~h}$ followed by plating the serial dilutions on NA. Twenty four morphologically distinct colonies were picked up after $24-72 \mathrm{~h}$ at $30^{\circ} \mathrm{C}$ and the individual cultures were further ascertained for alcohol tolerance by suspending the $48-72 \mathrm{~h}$ colony growth in $90 \%$ ethanol followed by spotting on NA. These cultures were further purified through three rounds of streaking and single colony selection on NA 
during which additional six colony morphotypes were identified. Thus altogether 30 single-colony isolations were taken up which were coded as $2 \times$ WM-ARB 01-30.

\subsection{Identification of Bacteria}

For identification, 16S rRNA partial gene sequencing homology analysis was adopted. For this, bacterial DNA was isolated from 1 - 2 day old colony growth on NA from selected 10 distinct colony types employing the Bacterial Genomic DNA kit (Axygen Scientific, Inc., Union City, CA) and the 16S rDNA was amplified in $50 \mu \mathrm{l}$ reaction using 27F (5'-AGAGTTTGATCCTGGCTCAG-3') and 1492R (5'GGYTACCTTGTTACGACTT-3') primers as described elsewhere [8]. The partial 16S rRNA gene sequences were subjected to Microbial Nucleotide BLAST analysis at the National Centre for Biotechnological Information (NCBI) and the identity was established based on $\geq 99 \%$ similarity to the closest species [8] [10]. The 16S rRNA gene sequences of the organisms have been deposited with the NCBI Genbank with the accession numbers KJ961504 to KJ961513.

\subsection{Testing the Long-Term Survivability of Bacteria in Ethanol}

The selected ten isolates were tested for the long-term survival in alcohol using the 4 - 5 day old NA cultures in sporulation stage by suspending in $70 \%, 90 \%$ and $100 \%$ ethanol or rectified spirit ( $96 \%$ ethanol) and spotting on NA at weekly interval for 2 months. The experimental conditions were as described elsewhere [7].

\subsection{Seed Coat Removal and Surface Sterilization as a Measure to Check Bacillus Introduction}

The absence of bacterial growth from the surface-sterilized seeds but their emergence from the seedlings suggested the presence of seed coat as a cause for bacterial survival internally. Exploring if seed coat removal would help in alleviating the introduction of such internally inhabiting organisms, excision of seed coat with the use of a nail cutter was attempted prior to the surface sterilization. The seed kernel was subjected to 5 min of treatment with $\mathrm{NaOCl}$ (5\% available chlorine) and were cultured on agar-gelled MS basal medium $\left(30 \mathrm{~g} \cdot \mathrm{l}^{-1} \mathrm{su}-\right.$ crose) in tubes after six rinses in sterile water. Before culturing, the kernels were tested by directly imprinting on NA and thereafter by indexing the medium and the tissue from the resultant seedlings.

\section{Results}

\subsection{Isolation and Purification of Bacteria}

The seeds that were imprinted on NA following surface sterilization as well as the last wash solution did not show any bacterial growth which prima facie suggested efficient surface sterilization. Out of the 30 seeds cultured on MS basal medium, two seedlings displayed visible bacterial association while ten seedlings showed yellowish discoloration of medium or inconspicuous growth and the latter tested positive for bacteria during medium-indexing. All the above cultures were discarded as they suggested either inefficient surface sterilization or internal bacterial survival. The remaining 18 cultures proved negative for bacterial association during medium-indexing. Upon testing the tissue segments from these cultures, eight seedlings (44.4\%) displayed bacterial colony growth from the hypocotyl and cotyledon tissue and 13 seedlings (72.2\%) from the collar and root tissue within 2 - 3 days on NA (Figure 1). The colony growth grossly suggested the association of various organisms in different seedlings or tissue parts. In some cases, the growth appeared to be a single organism, but clearly a mixture in other instances.

The colony growth that emerged on NA from different seedlings after $3-4$ days of incubation at $30^{\circ} \mathrm{C}$ were confirmed for spore production under $1000 \times$ phase-contrast. The sporulating cultures were pooled and challenged with filter sterilized $90 \%$ alcohol for $24 \mathrm{~h}$ followed by plating the serial dilutions on NA. Twenty four distinct colonies were picked up after $24-72 \mathrm{~h}$ at $30^{\circ} \mathrm{C}$ and these were further taken through serial dilution in ethanol and plated on NA to check for culture purity and the selection of pure cultures (Figure 2). The selected single colonies were further ascertained for alcohol tolerance by suspending the 48 - $72 \mathrm{~h}$ colony growth in $90 \%$ ethanol followed by spotting on NA (Figure 3). Ten divergent colonies out of the original 30 single colonies which were typical of Bacillus spp. were short-listed and carried forward through three rounds of single colony selection with alcohol challenge each time. 


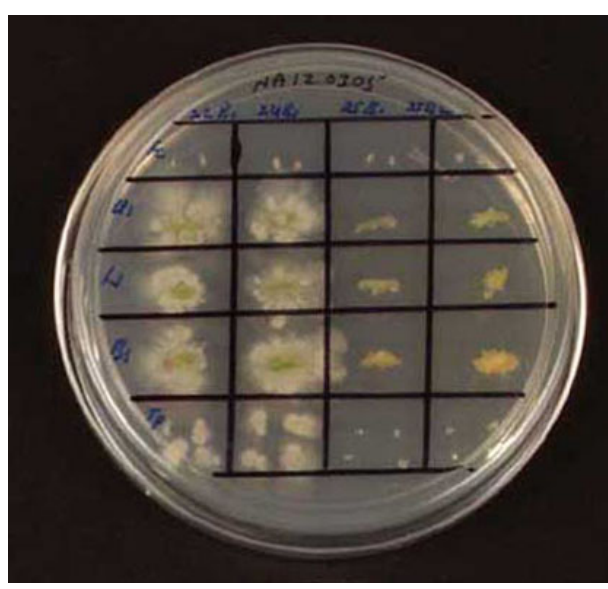

Figure 1. A view of the watermelon seedling indexing on nutrient agar employing tissue segments from different plant parts and of the medium. Row 1, testing of forceps for sterility prior to the usage; rows $2-4$, indexing of tissue from the shoot, collar and root tissue; row 5, indexing of culture medium employing disposable pipette tips.

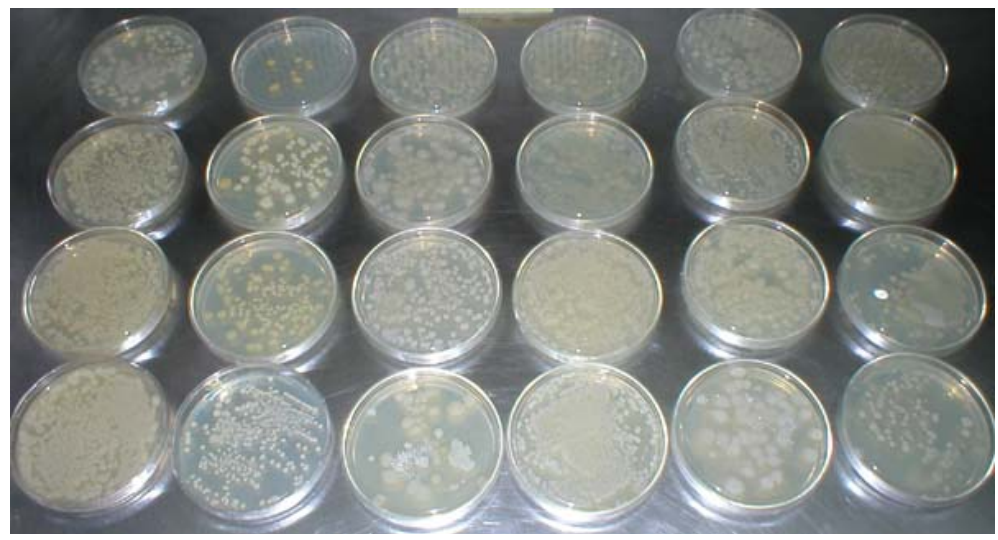

Figure 2. Diverse colony morphotypes derived after challenge inoculation of colony growth from the index-positive watermelon cultures with $90 \%$ ethanol.

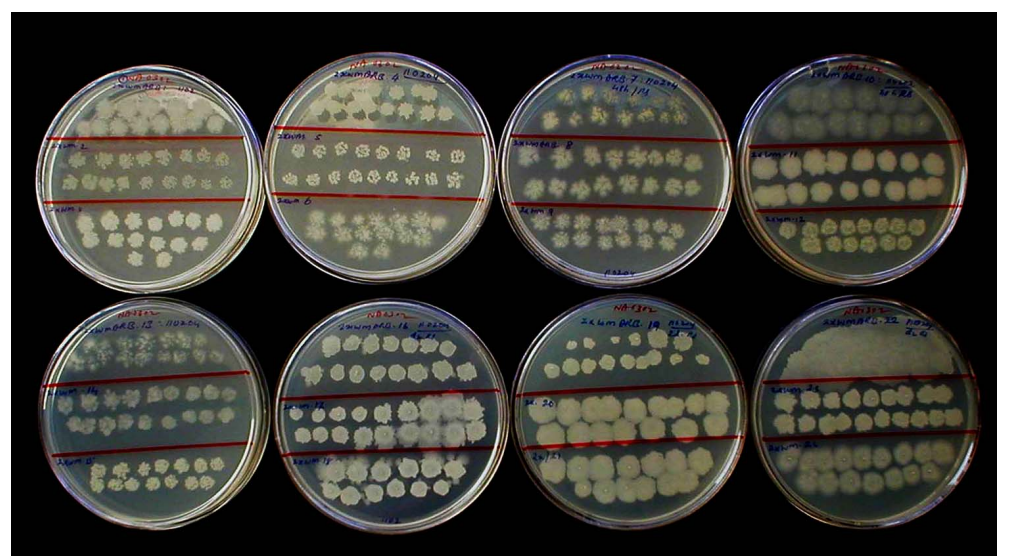

Figure 3. Bacterial isolates from watermelon spotted after challenge with $90 \%$ ethanol showing alcohol tolerance. 


\subsection{Identification of Bacteria}

The isolates belonged to four species including four each of B. pumilus and B. subtilis and one each of B. cereus and $B$. safensis as per the BLAST analysis results (Table 1). It appeared that even cultures which were morphologically distinct could belong to the same species as in the case of B. pumilus and B. subtilis.

\subsection{Testing the Long-Term Survivability of Bacteria in Ethanol}

All the organisms showed spore production and survival in 70\%, 90\% and 100\% ethanol or rectified spirit (96\% ethanol) for over two months of monitoring (data not presented). The observations thus endorsed the possibility of alcohol resistant Bacillus spp. entering the in vitro cultures of watermelon through apparently clean cultures as covert associates.

\subsection{Seed Coat Removal and Surface Sterilization}

The hard coat in watermelon seeds (dry) could be removed easily with the help of a nail cutter but it was not feasible to do so following surface sterilization or the wetting as the seeds became quite slippery and difficult to handle. The kernel was covered with a papery testa which got loosened and easily removed during the surface sterilization treatment employing NaOCl. The seed kernels cultured as above showed $100 \%$ germination and they appeared devoid of obvious contaminants. Shoot-tip cultures initiated on WPM from such cultures remained index-negative during the testing of medium and tissue in the next two sub-culture passages.

\section{Discussion}

The observations in this study confirms the possible introduction of hardy alcohol resistant Bacillus spp. in vitro through the aseptically grown watermelon seedlings as covertly associated organisms in the tissue culture medium or as epi/endophytes in the seedlings. The non-detection of bacterial colony growth on NA with the imprinting of $\mathrm{HgCl}_{2}$ treated seeds or upon plating the wash solutions indicated the effective surface sterilization at culture initiation. The emergence of bacterial growth from such seeds suggested their possible origin as intra-seed colonizers. Two of the organisms isolated here (B. pumilus and B. subtilis) belonged to the same species as documented with the long-term in vitro maintained triploid watermelon culture [10]. B. pumilus and B. safensis have also been isolated as endophytes from degenerating cultures of triploid watermelon [14]. The systematic monitoring of seedlings through visual examinations as well as medium- and tissue-indexing showed that a section of shoot-tips initiated from the index-negative seedlings tuned index-positive within 1 - 3 subculture cycles. Additionally, some of the shoot-tip cultures which were apparently clean initially showed up obvious contamination gradually. The above two situations could arise from the multiplication of organisms that were originally present in few numbers [11] or from the activation of organisms that were originally not cultivable as observed with the watermelon [14] and banana [15] systems.

Table 1. Identification of organisms retrieved from aseptically grown watermelon cv. Arka Manik seedlings as alcohol resistant bacteria as per partial 16S rRNA gene sequence homology analysis.

\begin{tabular}{|c|c|c|c|c|}
\hline No. & Isolate ID & $\begin{array}{l}\text { 16S rRNA } \\
\text { (bp) }\end{array}$ & Closest NCBI species identity \& homology ${ }^{\#}$ & $\begin{array}{l}\text { Suggested identification } \\
\text { and NCBI accession no. }\end{array}$ \\
\hline 1 & $2 \times$ WM-ARB02 & 605 & Bacillus pumilus (MTCC B603; CP007436; 99\%) & Bacillus pumilus (KJ961504) \\
\hline 2 & $2 \times$ WM-ARB03 & 715 & Bacillus pumilus (MTCC B603; СР007436; 99\%) & Bacillus pumilus (KJ961505) \\
\hline 3 & $2 \times$ WM-ARB07 & 650 & Bacillus pumilus (MTCC B603; СР007436; 99\%) & Bacillus pumilus (KJ961506) \\
\hline 4 & $2 \times$ WM-ARB08 & 940 & Bacillus pumilus (MTCC B603; СР007436; 99\%) & Bacillus pumilus (KJ961507) \\
\hline 5 & $2 \times$ WM-ARB14 & 815 & Bacillus cereus (FRI-35; NC018491; 100\%) & Bacillus cereus (KJ961508) \\
\hline 6 & $2 \times$ WM-ARB16 & 802 & Bacillus subtilis (PY79; NC022898; 100\%) & Bacillus subtilis (KJ961509) \\
\hline 7 & $2 \times$ WM-ARB26 & 798 & Bacillus subtilis (PY79; NC022898; 100\%) & Bacillus subtilis (KJ961510) \\
\hline 8 & $2 \times$ WM-ARB27 & 700 & Bacillus subtilis (PY79; NC022898; 100\%) & Bacillus subtilis (KJ961511) \\
\hline 9 & $2 \times$ WM-ARB28 & 741 & Bacillus subtilis (PY79; NC022898; 100\%) & Bacillus subtilis (KJ961512) \\
\hline 10 & $2 \times$ WM-ARB29 & 706 & Bacillus safensis (WM-249; KJ210642; 99\%) & Bacillus safensis (KJ961513) \\
\hline
\end{tabular}

\#NCBI match: scientific name followed by strain name, accession number and the per cent homology. 
Further, all the four organisms documented in this study were also isolated as covert tissue culture associates or as endophytes in other studies namely B. pumilus from grape [8], B. pumilus, B. subtilis and B. cereus from banana [15] and B. safensis from watermelon [14]. Spore-forming Bacillus spp. have been documented as endophytes and tissue culture contaminants in different plant species [2] [3] [5] [6] [16]. They are also common laboratory contaminants [17]. The results indicate that introduction of hardy spore forming bacteria in vitro is a common phenomenon warranting additional measures to control such organisms

The seed kernel in watermelon is enclosed in a papery membrane with an external seed coat and the organisms survived either exterior or interior to the kernel. The aspect of seed kernel colonization by bacterial endophytes, particularly the Bacillus spp., needs further investigations. In the tissue culture scenario, the visibly clean in vitro raised seedlings are generally taken forward for micropropagation or other in vitro applications as aseptic cultures, often without any specific testing for bacterial association. Indexing the medium and/or of the tissue from the unsuspecting cultures helps in identifying such potentially damaging cultures [11] [12]. Alcohol dip of tissue culture-culture handling tools as well as microbiological tools is a general practice in tissue culture units and microbiology laboratories. It is possible that the spores are carried on the culture handling tools to the alcohol wherein these hardy structures survive for long periods. With the recurrent use of same lot of alcohol, the extent of contaminants accumulates in alcohol and the brief flaming employed becomes inadequate to effectively remove the spores [5] [6]. The use of glass bead sterilizers is recommended as a safe and effective practice during tissue culture operations [6].

The surface sterilization treatment of watermelon seeds was improved after the extraction of seed kernel with the help of a nail cutter. This practice essentially needed the seeds to be dry as otherwise the mucous surface of wet seeds made them difficult to handle. The seed-kernel extraction also facilitated the use of $\mathrm{NaOCl}$ for surface sterilization treatment which otherwise tended to show high yellow exudation from the seed coat. This also helped in avoiding the usage of $\mathrm{HgCl}_{2}$ which is highly toxic with the residue issues.

\section{Conclusion}

This study brings out the possibility of in vitro introduction of alcohol-resistant spore forming hardy Bacillus spp. through the seedlings raised from watermelon seeds after adopting normal aseptic procedures. The removal of seed coat prior to the surface sterilization helped in checking the introduction of such hardy organisms.

\section{Acknowledgements}

This study formed a part of the Institute project 9.3.1. Tissue culture systems in horticultural crops with reference to management and exploitation of endophytes and was partly funded under the ICAR-AMAAS Network project "Basic and Applied Investigations on Endophytic Microorganisms in Horticultural Crops". This publication bears IIHR Contribution No. 47/2014.

\section{References}

[1] Leifert, C. and Woodward, S. (1998) Laboratory Contamination Management: The Requirement for Microbiological Quality Assurance. Plant Cell Tissue and Organ Culture, 52, 83-88. http://dx.doi.org/10.1023/A:1005905604043

[2] Leifert, C. and Cassells, A.C. (2001) Microbial Hazards in Plant Tissue and Cell Cultures. In Vitro Cellular Developmental Biology Plant, 37, 133-138. http://dx.doi.org/10.1007/s11627-001-0025-y

[3] Odutayo, O.I., Amusa, N.A., Okutade O.O. and Ogunsanwo, Y.R. (2007) Determination of the Sources of Microbial Contaminants of Cultured Plant Tissues. Plant Pathology Journal, 6, 77-81. http://dx.doi.org/10.3923/ppj.2007.77.81

[4] Davis, J.M. and Shade, K.L. (2000) Aseptic Techniques in Cell Culture. In: Spier R.E., Ed., Encyclopedia of Cell Technology, 1, Wiley, New York, 108-127.

[5] Singha, S., Bissonnette, G.K. and Double, M.L. (1987) Methods for Sterilizing Instruments Contaminated with Bacillus sp. from Plant Tissue Cultures. HortScience, 22, 659.

[6] Thomas, P. and Aswath, C. (2013) Alcohol-Mediated Horizontal Spread of Bacillus Spores and Assessing the Recurrent Sterilization Needs of Culture-Handling Tools Contaminated with Hardy Spores. Proceedings National Academy of Sciences, India, Section B: Biological Sciences, 83, 207-213. http://dx.doi.org/10.1007/s40011-012-0121-2

[7] Thomas, P. (2012) Long-Term Survival of Bacillus Spores in Alcohol and Identification of 90\% Ethanol as Relatively More Spori/Bactericidal. Current Microbiology, 64, 130-139. http://dx.doi.org/10.1007/s00284-011-0040-0

[8] Thomas, P. (2004) Isolation of Bacillus pumilus from in Vitro Grapes as a Long-Term Alcohol-Surviving and Rhizo- 
genesis Inducing Covert Endophyte. Journal of Applied Microbiology, 97, 114-123. http://dx.doi.org/10.1111/j.1365-2672.2004.02279.x

[9] Thomas, P. (2006) Isolation of an Ethanol-Tolerant Endospore-Forming Gram-Negative Brevibacillus sp. as a Covert Contaminant in Grape Tissue Cultures. Journal of Applied Microbiology, 101, 764-774. http://dx.doi.org/10.1111/j.1365-2672.2006.02993.x

[10] Thomas, P. (2007) Isolation and Identification of Five Alcohol Defying Bacillus spp. Covertly Associated with in Vitro Culture of Seedless Watermelon. Current Science, 92, 983-987.

[11] Thomas, P. (2004) In Vitro Decline in Plant Cultures: Detection of a Legion of Covert Bacteria as the Cause for Degeneration of Long-Term Micropropagated Triploid Watermelon Cultures. Plant Cell Tissue and Organ Culture, 77, 173179. http://dx.doi.org/10.1023/B:TICU.0000016824.09108.c8

[12] Thomas, P., Prabhakara, B.S. and Pitchaimuthu, M. (2006) Cleansing the Long-Term Micropropagated Triploid Watermelon Cultures from Covert Bacteria and Field Testing the Plants for Clonal Fidelity and Fertility during the 7 - 10 Year Period in Vitro. Plant Cell Tissue and Organ Culture, 85, 317-329. http://dx.doi.org/10.1007/s11240-006-9083-5

[13] Murashige, T. and Skoog, F. (1962) A Revised Medium for Rapid Growth and Bioassays with Tobacco Tissue Cultures. Physiologia Plantarum, 15, 473-497. http://dx.doi.org/10.1111/j.1399-3054.1962.tb08052.x

[14] Thomas, P. (2011) Intense Association of Non-Culturable Endophytic Bacteria with Antibiotic-Cleansed in Vitro Watermelon and Their Activation in Degenerating Cultures. Plant Cell Reports, 30, 2313-2325. http://dx.doi.org/10.1007/s00299-011-1158-z

[15] Thomas, P., Swarna, G.K., Roy, P.K. and Prakash, P. (2008) Identification of Culturable and Originally Non-Culturable Endophytic Bacteria Isolated from Shoot Tip Cultures of Banana cv. Grand Naine. Plant Cell Tissue and Organ Culture, 93, 55-63. http://dx.doi.org/10.1007/s11240-008-9341-9

[16] Leifert, C., Waites, W.M. and Nicholas, J.R. (1989) Bacterial Contaminants of Micropropagated Plant Cultures. Journal of Applied Bacteriology, 67, 353-361. http://dx.doi.org/10.1111/j.1365-2672.1989.tb02505.x

[17] Thomas, P., Mujawar, M.M., Upreti, R. and Sekhar, A.C. (2013) Improved Recovery of Bacillus Spores from Nonporous Surfaces with Cotton Swabs over Foam, Nylon, or Polyester, and the Role of Hydrophilicity of Cotton in Governing the Recovery Efficiency. Applied and Environmental Microbiology, 79, 381-384. http://dx.doi.org/10.1128/AEM.02626-12 
Scientific Research Publishing (SCIRP) is one of the largest Open Access journal publishers. It is currently publishing more than 200 open access, online, peer-reviewed journals covering a wide range of academic disciplines. SCIRP serves the worldwide academic communities and contributes to the progress and application of science with its publication.

Other selected journals from SCIRP are listed as below. Submit your manuscript to us via either submit@scirp.org or Online Submission Portal.
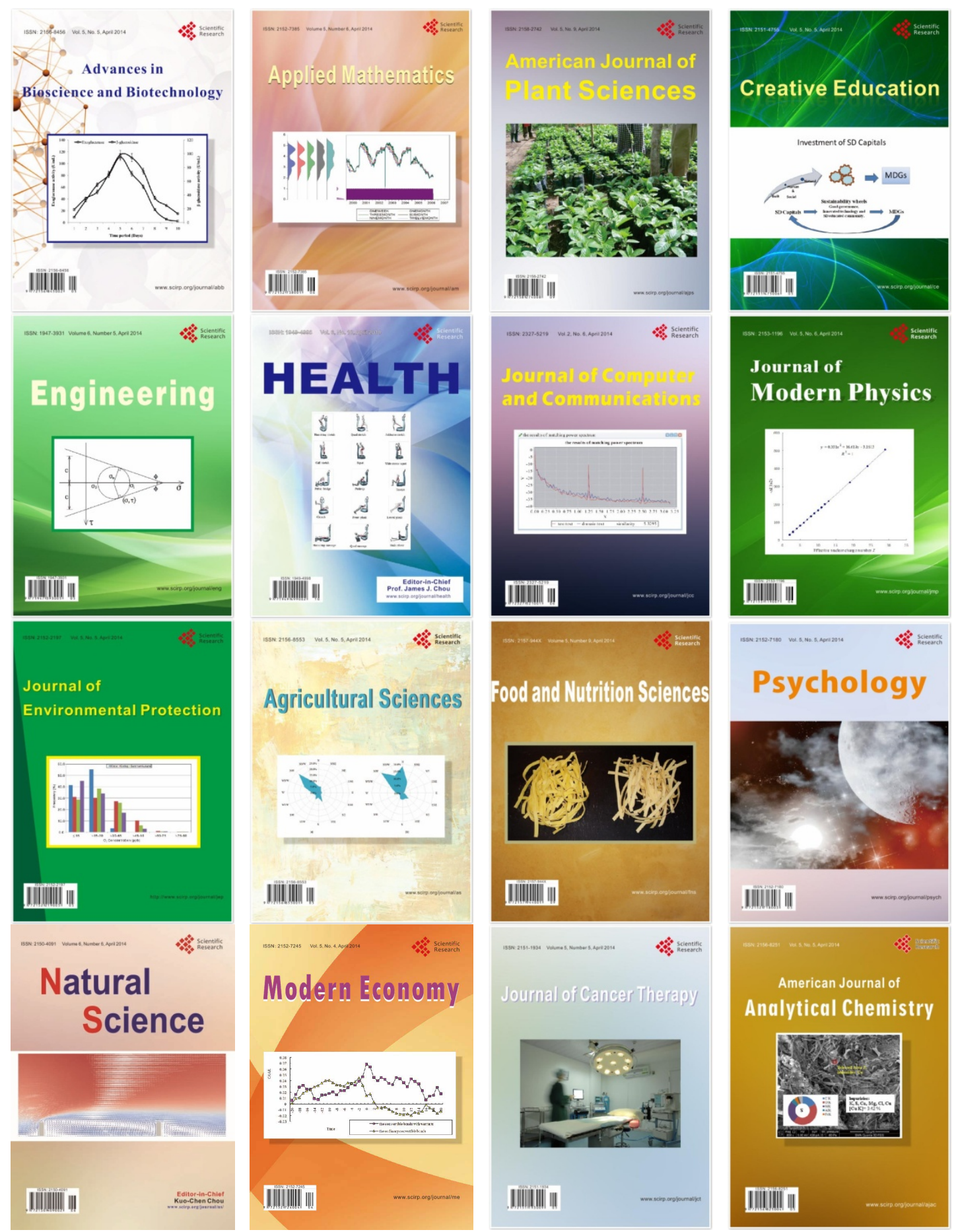